\title{
Wound Healing Activity of Herbal Ointment Containing the Extracts of Hibiscus rosa-sinensis Flowers and Curcuma longa Rhizomes
}

\author{
Fazlina Mustaffa ${ }^{1, *}$, Subramani Parasuraman', Geethaa Sahgal ${ }^{2}$
}

\section{Fazlina Mustaffa ${ }^{1, *}$, Subramani Parasuraman', Geethaa Sahgal ${ }^{2}$}

'Department of Pharmacology, Faculty of Pharmacy, Asian Institute of Medical Sciences and Technology (AIMST) University-Kedah, MALAYSIA.

2Department of Pharmaceutical Technology, Faculty of Pharmacy, Asian Institute of Medical Sciences and Technology (AIMST) University-Kedah, MALAYSIA.

\section{Correspondence}

\section{Dr. Fazlina Mustaffa}

Department of Pharmacology, Faculty of Pharmacy, Asian Institute of Medical Sciences and Technology (AIMST) University-Kedah, MALAYSIA

Phone no: +60-0174361869

E-mail: fazlina_harris@yahoo.com

\section{History}

- Submission Date: 17-11-2020:

- Review completed: 09-12-2020;

- Accepted Date: 23-12-2020.

\section{DOI : 10.5530/fra.2020.2.15}

\section{Article Available online}

http://www.antiox.org

\section{Copyright}

(C) 2020 Phcog.Net. This is an openaccess article distributed under the terms of the Creative Commons Attribution 4.0 International license.

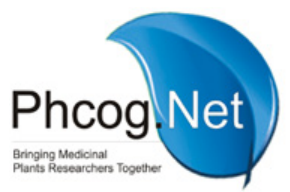

\begin{abstract}
Objectives: To evaluate wound healing activity of herbal ointment containing the extracts of Hibiscus rosa-sinensis flowers and Curcuma longa rhizomes. Methodology: H. rosa-sinensis flowers and C. longa rhizomes were extracted using $95 \%$ ethanol. H. rosa-sinensis and C. longa ointment were prepared using paraffin wax, lanolin and petroleum jelly. Ointment formulation was applied once daily on the excision wound made on Sprague Dawley rats for 20 days. Results: On day 20, the treatment group showed a significant increase in wound contraction which was $93.52 \pm 1.38 \%$ when compared to control (87.62 $\pm 1.48 \%)$. Conclusion: Herbal ointment exhibited significant wound healing activity in rat excision wound model.

Key words: Hibiscus rosa-sinensis, Curcuma longa, Wound healing.
\end{abstract}

\section{INTRODUCTION}

Herbs are a source of drug for a millennium years. From ancient times, man has used a wide range part of plants for the treatment as well as prevention of various ailments. Lately, there has been a great interest of scientific community in exploring the pharmacological activities of medicinal plants including the wound healing activity to establish the claims made about them in folklore medicines. ${ }^{1}$

Wounds can be described as cut or breaks in continuity of any tissue which are caused by physical, chemical, microbial, immunological or thermal insult to the tissue. ${ }^{2}$ Wound healing is an action involves in repairing that follows injury to the skin and other soft tissues. Proper wound healing activity act as an important role in the restoration of disrupted anatomical continuity as well as disturbed functional status of skin. The aim of wound management is to heal the wound in a time as short as possible; at the same time, to minimize the pain, discomfort and chance of forming scars.

Hibiscus rosa-sinensis known informally as Chinese hibiscus, China rose and shoeblack plant. Flowers were reported to be effective in hypertension treatment and possessed a good antifertility effect. $^{3}$ Furthermore, hibiscus acts as antioxidant, expectorant with mild laxative and diuretic effect. It was also found to decrease cholesterol levels. The antioxidant, anticancer and anti-inflammatory activity of $H$. rosa-sinensis was also reported. ${ }^{4}$

Curcuma longa is known as kunyit in Malaysia. Aggarwal et al. (2013) have investigated on antiinflammatory and anticancer activities of curcumin. ${ }^{5}$
Furthermore, the antimicrobial, antioxidant, antimutagenic, antidiabetic and hepatoprotective activity had been reported. ${ }^{6}$

Many studies had reported the wound healing effect of $H$. rosa-sinensis and C. longa and supported their respective traditional usage. ${ }^{7-12}$ However, up to date there is no research to provide evidence on wound healing properties of extract combination of $\mathrm{H}$. rosasinensis and C. longa. Hence, this research is planned to investigate wound healing activity of combination of herbal ointment containing the extracts of Hibiscus rosa-sinensis flowers and Curcuma longa rhizomes.

\section{MATERIALS AND METHODS}

\section{Extraction of Plant Materials}

H. rosa-sinensis flowers were collected in AIMST University, Kedah Darul Aman, Malaysia. The flowers petals were separated from the calyx, anther and stigma. Flowers petals were washed, wiped dry and further dried in hot air oven at $45^{\circ} \mathrm{C}$. Then, the dried flower petals were blended into fine powder. The powdered flowers were extracted by maceration using $95 \%$ ethanol as the solvent for $48 \mathrm{hr}$ and repeated 3 times. Later, filtrate was collected and evaporated on water bath at $40^{\circ} \mathrm{C}$ till a semi-solid extract was obtained. The percentage yield of the ethanolic extract of flowers of $H$. rosa-sinensis is 8.95 $\mathrm{g}$ w/v.

C. longa was purchased from Bedong local market. Rhizomes of C. longa were washed, wiped, dried and blended into smaller pieces by using blender. Then, 
the blended pieces were then dried in hot air oven at $45^{\circ} \mathrm{C}$. Then, the dried rhizomes were blended into fine powder. The powdered rhizomes were extracted by maceration using $95 \%$ ethanol as the solvent for 48 $\mathrm{hr}$ and repeated 3 times. Later, filtrate was collected and evaporated on water bath at $40^{\circ} \mathrm{C}$ till a semi-solid extract was obtained. The percentage yield of the ethanolic extract of rhizomes of C. longa is $15.26 \mathrm{w} / \mathrm{v}$.

\section{Preparation of ointment}

Paraffin wax was placed in evaporating dish and melted on water bath. After melting of paraffin wax, lanolin $(1.5 \mathrm{~g})$, cetostearyl alcohol $(1.5 \mathrm{~g})$, paraffin wax $(1.5 \mathrm{~g})$ and petroleum jelly $(25.5 \mathrm{~g})$ were added and mixed homogeneously. Thereafter, $H$. rosa-sinensis (100 mg) and C. longa (100 mg) extract were weighed and mixed with ointment base by using mortar and pestle.

\section{Animal}

Healty, male Spring dawley rats weigint $180 \pm 20 \mathrm{~g}$ were used for the experiment. The animal were kept in clean and dry cages and maintained with $12 \mathrm{~h}$-light-12 h dark cycle. Rats were fed with rat pellet and water ad libitium. The experiment protocol was approved by the AIMST University Human and Animal Ethics Committee (Approval number: AUHAEC/ FOP/ 2019/ 04).

\section{Excision Wound Creation}

The animals were anesthetized by using diethyl ether. After a few seconds, the dorsal fur of animals was removed, the anticipated area $\left(\sim 500 \mathrm{~mm}^{2}\right)$ of wound to be created was outlined on the back of animals. Then, the wound was created by cutting away full thickeness of skin along the markings area and (5 $\mathrm{mm}$ diameter) and the wound was left undressed to open environment. Each rat was placed in separated cage after the wound creation. ${ }^{13}$

\section{Wound Healing Activity}

After wound creation, the animals were divided into 3 groups of five each. The animals of group I served as wound control group which were left untreated, group II as standard drug treated group which were applied with povidone-iodine solution while animals of group III were test group and applied with herbal ointment. The ointment was topically applied to the animals once a day for a period of 20 days, starting from second days of the wound creation.

\section{Measure of Wound Contraction}

Wound contraction was examined by measuring the wound area on the alternate days. Transparent paper was used to trace the excision wound margin and the area measured by using graph paper. ${ }^{14}$ The changes in wound area was expressed in $\mathrm{mm}^{2}$. Wound contraction was expressed as percentage of original wound reduction and calculated using the formula below.

$\%$ of wound contraction $=$ Initial wound size - Specific day wound size

$$
\text { Initial wound size }
$$

\section{Statistical Analysis}

Data were expressed as mean \pm standard error of mean (SEM) for five animals per group. Statistical analysis was made using one-way analysis of variance (ANOVA) followed by Tukey's post hoc test. $P$-value $<0.05$ was considered to be statistically significance.

\section{RESULTS}

The measurements of the wounds treated with povidone-iodine solution and herbal ointment are presented in Table 1. The excision wound rats applied with the herbal ointment and povidone-iodine showed a significant wound healing activity when compared with that of control animals on day 8 onwards. Herbal ointment showed significant percentage closer activity from day 4 of the experiment and povidoneiodine solution significant percentage closer activity from day 8 of the experiment onwards when compared with that of that of control (Figure 1).

\section{DISCUSSION}

Wound healing is defined as restoration of damage tissue to its original state which is initiated by stimulus of tissue injuries. ${ }^{13}$ Connective tissue repair process involves four stages which are coagulation to prevent loss of blood, inflammation and removal of foreign substance from skin (debridement), epithelial repair and lastly remodeling of tissue and deposition of collagen. The agents having properties to accelerate these stages are known as promoter of wound healing. ${ }^{14}$

Treatment group showed significant increase in wound contraction when compared to control on $8^{\text {th }}$ day onwards. Wound healing activity of $H$. rosa-sinensis and $C$. longa herbal ointment might be due to antioxidant potential of both this plant. ${ }^{15,16}$ Wound healing process consists of cell proliferation, suppression of inflammation and collagen contraction and these can be delayed by antioxidants. During inflammation, neutrophils and cytokines produce reactive oxygen species (ROS) as well as reactive nitrogen species (RNS) which are acting as free radicals that exacerbate damage and inhibit tissue remodelling. ${ }^{17}$ ROS can cause inactivation of enzymes, breakage of DNA as well as lipid peroxidation which will retard optimum wound healing process. In this case, antioxidants are useful to diminish the damage caused by oxidative stress thus enhance the healing process. The redox properties of antioxidant enable them to act as reducing agents, hydroxyl radicals and superoxide radical scavengers.

\begin{tabular}{|c|c|c|c|}
\hline \multirow{2}{*}{$\begin{array}{l}\text { Days after } \\
\text { infliction of } \\
\text { wound }\end{array}$} & \multicolumn{3}{|c|}{ Wound area $\left(\mathrm{mm}^{2}\right)$} \\
\hline & Control & Povidone-iodine & Herbal ointment \\
\hline 2 & $521.20 \pm 10.84$ & $519.20 \pm 10.80$ & $525.60 \pm 11.78$ \\
\hline 4 & $453.80 \pm 13.25$ & $411.60 \pm 13.71$ & $401.80 \pm 14.66$ \\
\hline 8 & $335.8 \pm 9.07$ & $264.80 \pm 9.57^{\star *}$ & $272.60 \pm 12.52^{\star *}$ \\
\hline 16 & $211.40 \pm 11.77$ & $150.20 \pm 12.71^{* *}$ & $140.20 \pm 8.97^{\star *}$ \\
\hline 20 & $114.60 \pm 9.47$ & $40.60 \pm 3.54^{\star * *}$ & $39.80 \pm 5.21^{* * *}$ \\
\hline
\end{tabular}

The values are given as mean $\pm \operatorname{SEM}(n=5) .{ }^{* *} p<0.01$ and ${ }^{* * *} p<0.001$ compared with controls (One-way ANOVA followed by Tukey's post hoc test)

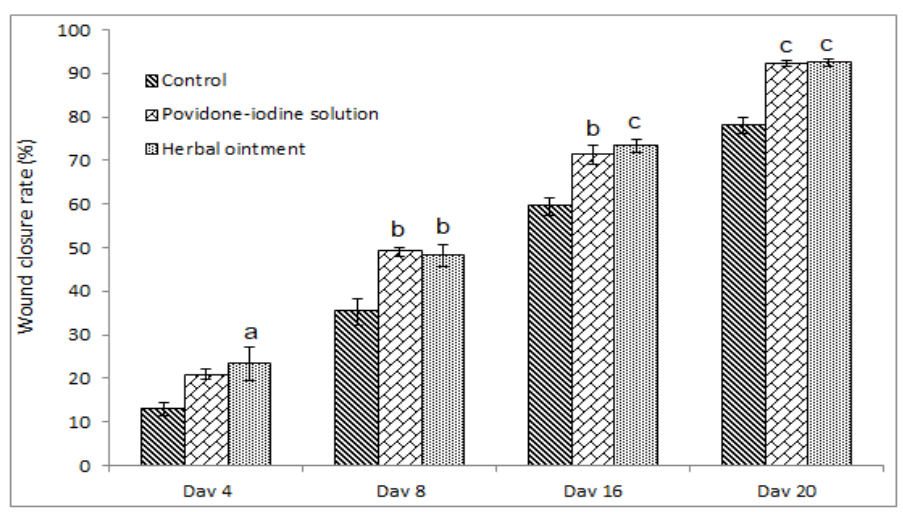

Figure 1: Wound healing activity of herbal ointment as comparison with positive and negative control.

The values are given as mean \pm SEM $(n=5) .{ }^{a} p<0.05 ;{ }^{b} p<0.01$ and ${ }^{c} p<0.001$ compared with controls (One-way ANOVA followed by Tukey's post-hoc test) 
Therefore, the better wound healing effect of treatment group may be due to the antioxidant properties in both $\mathrm{H}$. rosa-sinensis and C. longa.

Under usual physiological condition, inflammatory phase is the vital stage in wound healing process to eliminate the necrosis tissue debris as well as micro-organism. Nevertheless, prolonged inflammation will disturb or delay healing process severely and lead to increased fibrosis and scarring. Many research studies have proved the significant antiinflammatory properties of C. longa. Wound that treated with $C$. longa containing curcumin showed a higher number of macrophage, neutrophils and fibroblast cells than the untreated wound. These infiltrating cells producing a variety of potential growth factors which is necessary for modulation of biological processes during wound healing. For example, transforming growth factor-beta (TGF- $\beta$ ) and epidermal growth factor (ECG) are important to stimulate the synthesis of fibronectin (FN) as well as collagen and hence elevate granulation tissue formation. ${ }^{18}$ Hence, this anti-inflammatory effect may contribute to the wound healing acceleration in treatment group.

Gandhi et al. has reported the individual wound healing activity of H. rosa-sinensis to be $78.26 \%$ for $5 \% \mathrm{w} / \mathrm{w}$ extract on $12^{\text {th }}$ day. ${ }^{19}$ The comparison of this study taking into account the previous study, the individual extract $(78.26 \%)$ wound healing activity was weaker than combination herbal ointment (93.13\%). Thus, it may be concluded that combination of extract shows synergistic effect in promoting wound healing.

\section{CONCLUSION}

Herbal ointment showed showed a significant wound healing activity on excision wounds in rats.

\section{ACKNOWLEDGEMENT}

This research was supported by AIMST University, Malaysia.

\section{CONFLICT OF INTEREST}

The authors declare no conflict of interest.

\section{ABBREVIATIONS}

H. Rosa sinensis: Hibiscus Rosa sinensis; C. Longa: Curcuma longa; TGF$\beta$ : Transforming growth factor-beta; ECG: Epidermal growth factor; FN: fibronectin; RNS: Reactive nitrogen species; ROS: Reactive oxygen species.

\section{REFERENCES}

1. Chah KF, Eze CA, Emuelosi CE, Esimone CO. Antibacterial and wound healing properties of methanolic extracts of some Nigerian medicinal plants. J Ethnopharmacol. 2006;104 (1-2):164-7.

2. Bhimani B, Prajapati C, Sabale P, Sabalea V. An overview of medicinal plants as wound healers. J Appl Pharm Sci. 2012;2(11):143-50.

3. Jadhav VM, Thorat RM, Kadam VJ, Sathe NS. Traditional medicinal uses of Hibiscus rosa-sinensis. J Pharm Res. 2009;2(8):1220-2.

4. Pearline D, Kamat N, Thiagarajan, P. Rosa Sinensis (Hibiscus): A versatile Indian origin plant. J Chem Pharm Sci. 2015;8(4):970-4

5. Aggarwal BB, Gupta SC, Li S, Yuan W. Curcumin-free turmeric exhibits antiinflammatory and anticancer activities: Identification of novel components of turmeric. Mol Nutr Food Res. 2013;57(9):1529-42

6. Hosea ZY, Kator L, Rhoda EH. Phytochemical Properties and Antimicrobial Activities of Aqueous Extract of Curcuma longa (Turmeric) Rhizome Extract. Asian J Res Crop Sci. 2018;2(1):1-8.

7. Bhaskar A, Nithya V. Evaluation of the Wound Healing Activity of Hibiscus rosa-sinensis L (Malvaceae) in Wistar Albino Rats. Indian J Pharmacol. $2011 ; 44(6): 694$

8. Chalapathi RAV, Shivanada NB, Sivachandra RS, Orette FA. Effects of Hibiscus rosa-sinensis L (Malvaceae) on Wound Healing Activity: A Preclinical Study in a Sprague Dawley Rat. IJLEW. 2007;6(2):76-81.

9. Ahmed S, Ahmed T, Hossan T, Nahar T, Paul S, Uddin B. Antibacterial activity of the ethanol extracts of Hibiscus rosa-sinensis leaves and flowers against clinical isolates of bacteria. Bangladesh J Life Sci. 2010;22(2):65-73.

10. Gajalakshmi K, Ruban P. In-vitro Antibacterial activity of Hibiscus rosasinensis flower extract against human pathogens. Asian Pac J Trop Biomed. 2012;2(5):399-403.

11. Chibuzo N, Ikpeama A, Onwuka GI. Nutritional Composition of Tumeric (Curcuma longa) and its Antimicrobial Properties. Int J Eng Res. 2014;5(10):1085-9.

12. Aslam MN, Barron A, Bhagavathula N, DaSilva M, Johnson KJ, McClintock SD, et al. A Combination of curcumin and ginger extract improves abrasion wound healing in corticosteroid impaired hairless rat skin. Wound Repair Regen. 2009; 17(3):360-6

13. Ganesan S, Parasuraman S, Maheswaran SU, Gnanasekar N. Wound healing activity of Hemidesmus indicus formulation. J Pharmacol Pharmacother. 2012;3(1):66-7.

14. Chaurasiya PK, Jain A, Pawar RS, Rajak H, Singour PK, Toppo FA. Wound healing activity of Sida cordifolia Linn. in Rats. Indian J Pharmacol. 2013;45(5):474-8.

15. Gupta A, Kumari A, Singh S, Verma, R. Antimicrobial potential of Hibiscus rosaSinensis L. in western Himalaya. Biol Forum. 2019;11(1):35-40.

16. Menon VP, Sudheer AR. Antioxidant and anti-inflammatory properties of curcumin. Adv Exp Med Biol. 2007;595:105-25.

17. Khadabadi IA, Farooqui VP, Nalamwar HA, Sawarkar HA. Development and evaluation of herbal wound healing formulations. IJPTB. 2009;1(4):1104-8.

18. Maheshwari RK, Singh AK, Gaddipati J, Srimal RC. Multiple biological activities of curcumin: A short review. Life Sci. 2005;78(18):2081-7.

19. Gandhi SP, Chitlange SS, Reche AP. Antimicrobial and wound healing activity of Hibiscus rosa-sinensis Linn. J Pharm Res. 2018;12(7):929-35.

\section{SUMMARY}

- This research was anticipated to determine the wound healing activity of herbal ointment containing the extracts of Hibiscus rosa-sinensis flowers and Curcuma longa rhizomes.

- This current research showed that the combination of H. rosa-sinensis and C. longa ointment could be used as natural wound healing agent.

\section{ABOUT AUTHORS}

Dr. Fazlina Mustaffa, is a lecturer in the Department of Pharmacology, Faculty of Pharmacy, AIMST University, Malaysia. Her research interest is in the areas of plant extracts antimicrobial activity and toxicological studies.

Dr. Subramani Parasuraman, is a Associate Professor in the Department of Pharmacology, Faculty of Pharmacy, AIMST University, Malaysia. His research interest is in the areas of pre-clinical pharmacodynamics and toxicological studies.

Dr. Geethaa Sahgal is a lecturer in the Department of Pharmaceutical Technology, Faculty of Pharmacy, AIMST University, Malaysia. Her research interest is in the areas of plant extracts antimicrobial activity and toxicological studies.

Cite this article: Mustaffa F, Parasuraman S, Sahgal G. Wound Healing Activity of Herbal Ointment Containing the Extracts of Hibiscus rosa-sinensis Flowers and Curcuma longa Rhizomes. Free Radicals and Antioxidants. 2020;10(2):86-8. 